\title{
Economic justification of costs at inspection of industrial safety of high-rise marine structures
}

\author{
Pavel Garibin ${ }^{1}$, Evgeniy Ol'khovik ${ }^{1,{ }^{*}}$ and Igor Rastorguev ${ }^{1}$ \\ ${ }^{1}$ Admiral Makarov State University of Maritime and Inland Shipping, Hydraulics Structures \\ Department, 198035, Saint-Petersburg, Russia
}

\begin{abstract}
The task of technical and economic regulation within mutual international recognition of testing laboratories are considered. Codes and procedures within requirements of international ISO/IEC standards of a series 17000 for elimination of non-tariff barriers and interlaboratory exchange of experts in the field of high-rise marine construction are considered. In paper, the methods of assessment of formation of economically justified cost of works at inspection and monitoring of technical condition of high-rise marine wharf engineering port structure based on settlement and actual labor input were applied. For the countries of $\mathrm{EU}$, data on the average cost of works of testing laboratory within a week have been taken as a basis. Such approach will be objective as considers only expenses on obligatory actions in the course of inspection of technical condition of port engineering constructions. The analysis of public results of financial activities of the accredited organizations allowed to calculate the main indicators of the size of necessary profit and overheads at observance of all requirements imposed to test laboratories including taking into account their future technical development. The offered practice corresponds to the general direction by mutual international recognition of independent testing laboratories and can be use in the future.
\end{abstract}

\section{Introduction}

Ensuring of industrial safety is an actual problem as it affects the most important aspects of human life. Modern system researches of economy of industrial safety [1] and industrial accidents [2] are known since the beginning of the 80th years. In article [3] the economic measures which belong to designing of industrial processes and ensuring of their safety are considered. The quantitative criteria based on consequences simulation and in total with the economic indicators with use of multi-purpose optimization of programming are offered. The NSGA-II algorithm [4] it can be obtained as the procedure of optimization for which the amalgamation of the emergency costs calculation for various constructive schemes included a high-rise construction and marine overhead road is offered.

In work [6] authors consider economic and technical solutions for a possibility of prolongation of service life of safety of crucial components when they reach the termination of life term. The qualified decision about continuous work outside the service life is offered

\footnotetext{
* Corresponding author: OlhovikEO@gumrf.ru
} 
to be carried out based on estimates on two indexes: instrument assessment of technical condition and economic assessment of benefit.

In paper [7] authors on the example of Shenzhen's port consider the questions of assessment of the economic losses in the industry related to destruction of marine port, recommendations on risk management based on a statistical approach and a comprehensive analysis of Petri Net are offered.

There is no uniform and centralized system for technical safety assessment for the maritime Port of Seattle in article [8] (the Pier and wharf structures belong to different owners), that leads to some problems. So, in case when one part of port pier is in unsatisfactory technical condition it naturally influences industrial safety of the adjacent constructions and all infrastructure of port in general. Financial consequences of remedial measures for business and engineering practice were offered.

The similar idea was checked in work [9] where the damping properties of the wharf 375 meters long were investigated. Although the wharf was designed as a number of independent sections, the research had shown that the construction part and pipelines located on the top part of the wharf connected the adjacent sections together and had significant effect on dynamic behaviour, especially in the longitudinal direction. In current time in Russia there are about 10 thousand port hydraulic engineering constructions (on river and at marine), at the same time about $30 \%$ from them are in a critical condition and another $30 \%$ have restriction at operation. The similar situation takes place in other countries, where the main trend is the decommissioning (closing) of small port objects and transfer of freights to large port terminals, which are hubs and overload several million tons of freight per year.

\section{Methods}

As the main method for determination of initial maximum cost of works in Russia uses the resource-indexed method or a way of the open auction (an auction with decrease), that we for the analysis used open data on tenders for the last five years. For the analysis of pricing in the European Union we used cost data handbooks of the base prices "RS Means" and "Spon's" which give the average prices for the last time period on the actual performed works.

All wharf structures are objects of technical regulation, their condition has to be checked with the set periodicity - examination procedure or confirmation of conformity. Carrying out of these procedures is an mandatory condition and it is under the supervision of federal or local authorities, but for objectivity the inspection is carried out by the test centres (laboratories) having accreditation according to the international standard ISO/IEC 17025:2005 "General requirements for the competence of testing and calibration laboratories" (in Russia - State Standard ISO/MEK 17025-2009).

Some states gradually reduce the responsibility for maintenance of transport safety by attraction to examination of private companies, and then they are responsible for complete responsibility for checks and cannot reduce standards on qualification of the specialists who are carrying out inspections. The similar tendency exists also in Russia, the requirements to experts are constantly supplemented, the assessment of qualification is partially brought out of control of self-regulatory organizations, checks by expert community become stricter, a part of examinations was transferred from regional to federal level. Moreover, federal and local authorities conduct work on introduction of economic interest for owners of hazardous production facilities.

In 2015 the European commission based on offers of national authorities of five countries created the Unified register of certification agencies and test laboratories of the EU where 950 certification agencies and 2300 test laboratories are working according to 34 Technical regulations. They issued 450 thousand certificates of conformity and registered 1.5 million conformity Declarations. 
The "Rapprochement of the technical regulation systems of and standardization of the EU and the Russian Federation" project (EuropeAid/132827/C/SER/RU) recommends to limit the scope of the technical regulation of the Customs union concerning buildings and constructions by only the basic requirements to buildings and constructions which will be the foundation for establishment of essential characteristics for construction materials and products in technical standards to these regulations, and also forms and schemes of conformity confirmation of construction materials and products, requirements to the state supervision, etc. The similar system of technical regulation in construction branch has been operating in Europe since 1989 (in Russia from 2009 in updated version).

Objective calculation of works cost shall include all costs incurred at implementation of port constructions inspection and besides according to the technological scheme of works performance accepted at the entity (described in the Quality Guidelines) because different types of works require various personnel qualification and use of the equipment. Our researches on change of works cost on examination and monitoring of marine and inland wharf structures for the last five years have shown the following:

- there is an increase in number of the organization's (test laboratories) rendering services in the field of examination of industrial safety that in turn increases the competition;

- the initial contractual cost of works on inspection of technical condition remains at one invariable level for a long time;

- price reduction (underbidding) is gradually increased during the tender procedures.

Phase 1: Preparation;

- the works connected with the conclusion of contractual commitments and ensuring of quality management.

Phase 2: Initial operations on inspection of technical condition;

- analysis of technical documentation;

- development of the program of inspection technical condition.

Phase 3: carrying out of visual inspection, measurement, surveying;

Phase 4: carrying out of instrumental inspection, test materials by non-destructive testing method;

Phase 5: cameral data processing and drawing up of reports;

Phase 6: registration of measurements protocols, delivery of work results to the customer, closing of the agreement.

Works on agreement of the accounting with the public supervisory authorities [10] and execution of conformity Declarations (currently these works are performed by the owner of construction or the organization which carries out exploitation).

The works on safety concerning the environment and work on automation of monitoring of port hydraulic engineering constructions [11] or the water area of approach channels [12] can be included as a part of the general works at carrying out inspection and monitoring according to the Russian acts of technical regulations (No. 384, 620,623) and the European Regulation (EU) No 305/2011.

For the purpose of an economic justification of expenses on examination of industrial safety of marine wharf structures it is offered to take as a basis the technological regulations of works by means of which to calculate specific labor input for standard objects and average cost of experts wage depending on their qualification. Such approach will be the most objective as considers only direct expenses on obligatory actions in the course of inspection of technical condition of marine wharf structures. At the same time all works can be estimate as percentage according to the offered partition on Phases that also provides objectivity as the part of works cannot be performed because of features of construction, i.e. it can be dispensable.

The statistical data of the state authority responsible for observations in the field of work and social protection were use for determination of the average level of the salary. For more 
objective assessment search was carried out for concrete regions. The labor market research, i.e. the analysis of open vacancies was carried out in addition.

In calculations there was used the following scheme which is direct calculation of salary only for the performed works on monitoring of industrial safety by group of specialists with separation into individual works:

$$
S L=\sum_{\mathrm{i}=1}^{\mathrm{n}} T_{\mathrm{ij}} \cdot C_{\mathrm{j}}
$$

where $\mathrm{SL}$ - personnel salary, $\mathrm{T}_{\mathrm{ij}}$ - labor input of $\mathrm{i}$ operation performance by $\mathrm{j}$ specialist, $\mathrm{C}_{\mathrm{j}}$ - average hourly earnings of $\mathrm{j}$ specialist (expert).

At the same time the following scheme was applied to the certain experts having various competences different the requirements imposed to the expert:

- labor input of operation performance by the expert was estimated with coefficient 1.0;

- labor input of operation performance by the engineer (in the field of tests or cameral processing) was estimated with coefficient 1.2 ;

- labor input of operation performance by the expert with considerable experience (the senior expert, the head of department, the chief engineer, etc.) was estimated with coefficient 0.8 .

Thus, all performed works were carried out conditionally by conventional "expert" that facilitated a possibility of calculation of labor input for other conditions, other object or other region.

As a result, the basic cost of works can be calculate on the following formula:

$$
C=\frac{T \times C_{j}}{K_{C}} \times(1+K p)
$$

where $\mathrm{C}$ - basic cost of works on monitoring of technical condition (examination of industrial safety); $\mathrm{T}$ - standard (specific) labor input, the amount of labor input of works on inspection in [persons] $\cdot\left[\right.$ hour]; $\mathrm{C}_{\mathrm{j}}$ - average hourly earnings of $\mathrm{j}$ specialist (expert); $\mathrm{K}_{\mathrm{C}}-$ the coefficient establishing a wages share in total costs for examination of industrial safety $(0.35 \div 0.5) ; \mathrm{K}_{\mathrm{P}}-$ the coefficient establishing a profit share in the cost of works - profitability $(0.1 \div 0.15)$.

For the accounting of special factors which complicate (simplify) the process of work performance on inspection of high-rise construction or marine overhead port engineering constructions, the additional coefficients can be applied to a formula (2), for example, depth of construction, weather conditions, the adverse period of year, etc.

\section{Results}

The offered concept for justification of works cost on confirmation of technical condition of constructions is more flexible and corresponds to modern recommendations as European commission, and norms which are applied to testing laboratories in Russia.

Our research confirmed the results of work [13], which was established strong correlation between the safety budget and the industrial accident rate enabled modelling of an industrial safety system with these variables as the input and the output, respectively.

The made analysis of practice for the last 3 years on several organizations has shown that the size of the overheads connected with the providing of quality of laboratory management and metrological requirements constitutes up to $25 \%$, and profit constitutes to $10 \%$. Such economic indicators provide high quality of works performance and scientific and technical development of enterprise, including training and retraining of personnel. Level of the salary fund depends on a similar indicator in the chosen region and can be adjuste by various coefficients. 
Always there is some interrelation between the level of industrial safety and the budgetary costs of monitoring. It is confirm as our researches of emergency cases for the last five years and the international practice - [14]. For maintenance of high level of safety of designs use of special systems of management [15] and project management, including and risk analysis is possible. Expenses on these actions have to be shifted to the owner of a design or the organization, which exercises control and operation. We compared the methods that were suggested in this paper with methods from well-known international agencies - «RS Means»[16] and «Spon's»[17], who publish the Engineering Price Book (or Cost Handbook) and obtained the correct correlation.

\section{Conclusions}

Offers on basic structure of works on examination of industrial safety of marine wharf structures are developed. The economic justification of costs is based on the acts of technological regulations of works performance and average compensation of experts and test laboratory. It is revealed that the actual cost of services of the test labs for inspection of technical condition of buildings and constructions can significantly differ depending on the country of stay. At the same time, the volume of the performed works according to technical regulations is approximately identical in the different countries. Different approach when determining and forming cost for basic works is the main reason for such distinction [18-20].

The essence of settlement determination of the price of technical inspection depends on the level of the salary of the experts who are directly carrying out technical observation. The problem of the international rapprochement of testing laboratories consists in creation of equally acceptable working conditions of experts, including and in compensation. This method has been used in this paper for what the analysis of a large number of works from inspection of technical condition of marine wharf engineering constructions has been made.

The proposed practice corresponds to the direction of mutual international recognition of independent testing laboratories.

\section{References}

1. Y. Walter On the economics of industrial safety. Law and Contemporary Problems. 38, 669 (1974)

2. J. Chelius The control of industrial accidents: Economic theory and empirical evidence. Law and Contemporary Problems. 38, 700 (1974)

3. S. Eini, H. Shahhosseini, M. Javidi, M. Sharifzadeh. Process Safety and Environmental Protection. 104, 254 (2016) doi: 10.1016/j.psep.2016.09.010

4. L. Pan, K. Li, W. Xue Multi-objective optimization for building performance design considering thermal comfort and energy consumption, 35th Chinese Control Conference (CCC), (2016) doi: 10.1109/ChiCC.2016.7553789

5. S. Eini, B. Abdolhamidzadeh, G. Reniers, D. Rashtchian Optimization procedure to select an inherently safer design scheme. Process Safety and Environmental Protection, 93 (2015) doi: 10.1016/j.psep.2014.05.002

6. M. Shafiee, I. Animah, N. Journal of Loss Prevention in the Process Industries. 44, 299 (2016) doi: 10.1016/j.jlp.2016.09.013

7. X. Tan, J. Lam, Y. Zhang Economic impact of port disruptions on industry clusters: A case study of Shenzhen. International Conference on Transportation Information and Safety (ICTIS), (2015) doi: 10.1109/ICTIS.2015.7232069 
8. C. Caudill, J. Hingle, S. Asavareungchai, A. Sidler The Execution of a Comprehensive Dock Condition Survey. Proceedings of Ports '13: 13th Triennial International Conference, (2013) doi: 10.1061/9780784413067.060

9. R. Boroschek, H. Baesler, C. Vega Experimental Evaluation of the Dynamic Properties of a Wharf Structure. Engineering Structures. 33, 344 (2011) doi: 10.1016/j.engstruct.2010.10.014

10. A. Nicholson Why Regular Inspection of Transportation Facilities is Critical to Public Safety. Structures Congress. (2006) doi: 10.1061/40889(201)161

11. P. Garibin, E. Ol'khovik, S. Shabanov The methodology of organization of continuous monitoring of technical state of hydraulic structures of water transport. News of higher educational institutions. Construction. 674, 58 (2015)

12. M. Champiri, S. Sajjadi, S. Mousavizadegan, F. Moodi Journal of Intelligent and Fuzzy Systems. 32, 1945 (2017) doi: 10.3233/JIFS-161411

13. A. Afonin, E. Ol'khovik, A. Tezikov Development of the assessment methods of anadromous depths on the northern sea route depending on the detail of survey of the bottom relief. Vestnik Gosudarstvennogo universiteta morskogo i rechnogo flota imeni admirala S.O. Makarova. 38, 62 (2016) doi: 10.21821/2309-5180-2016-8-4-62-68

14. G. Choi, B. Loh Control of Industrial Safety Based on Dynamic Characteristics of a Safety Budget-Industrial Accident Rate Model in Republic of Korea. Safety and Health at Work. (2016) doi:10.1016/j.shaw.2016.11.002

15. S. Bovteev, S. Kanyukova Development of methodology for time management of construction projects. Magazine of Civil Engineering. 62, 102 (2016) doi: 10.5862/MCE.62.10

16. Cost Planning and Estimating for Facilities Maintenance, RSMeans Data. (2016)

17. J. Smith, D. Jaggar, P. Love. Building cost planning for the design team. (2016)

18. C. Ghani, N. Zaimah, N. Myeda, A. Shah Ali. Operations and Maintenance Cost for Stratified Buildings: A Critical Review, MATEC Web of Conferences. 66, (20160

19. H. Krstić, S. Marenjak Analysis of buildings operation and maintenance costs. Građevinar. 64, 293 (2012)

20. A. Suffian Some common maintenance problems and building defects: Our experiences. Procedia Engineering, 54, 101 (2013) 